\title{
Replicate Imaging of a Unicellular Plant through a Glass Barrier Using Fine Iron Particles: Evidence for Electromagnetic Energy Transfer
}

\author{
Benjamin J. Scherlag, PhD ${ }^{1^{*}}$, Kaustuv Sahoo, PhD $^{2}$, Abraham A. Embi, BS, MBA/HA ${ }^{3}$ \\ ${ }^{1}$ Heart Rhythm Institute, University of Oklahoma Health Sciences Center, Oklahoma City, Oklahoma \\ ${ }^{2}$ Center for Veterinary Health Sciences, Oklahoma State University, Stillwater, Oklahoma \\ ${ }^{3} 13442$ SW 102 Lane Miami, FLA, 33186
}

*Corresponding author: Benjamin J. Scherlag, PhD, 1200 Everett Drive (6E103), Oklahoma City, OK, 73104, E-mail: benjamin-scherlag@ouhsc.edu

\begin{abstract}
Introduction: Previously we utilized a method for imaging electromagnetic fields from plant and animal tissues. We applied the same methodology to single cell organisms.

Methods: A clean glass slide served as a base. A coverslip was placed on the base. A drop of culture media containing the single cell plant, Euglena gracilis was placed on the coverslip and covered by another coverslip to enclose the organisms. A second coverslip "sandwich" (SDW) containing fine iron particles (mean diameter 2 microns) mixed with a potassium ferrocyanide iron staining solution was placed over the underlying coverslip SDW. The second SDW was offset so that a portion was not covering the area with the microorganism, thereby serving as a control. When all of the liquid had evaporated ( 24 - 48 hours) the area encompassed by the images of the encysted cells were quantified using the Image Pro-plus histomorphometry software program and compared to similar images of actual encysted cells from dried specimens for the same time periods (each group, $\mathrm{n}=5$ ).

Results: Initially we observed mobile, rod shaped, single cell organisms with rounded ends. After $24-48$ hours, the second coverslip showed images of the immobile of encysted, cells whose appearances were identical and whose area measurements were not significantly different $(\mathrm{p} \geq 0.6)$ than the actual encysted cells.

Conclusions: These finding demonstrate that replicate images of the single cell plant, Euglena gracilis, can be retrieved through a glass barrier. The evidence suggesting that electromagnetic energy may provide a possible mechanism underlying these replicate images is illustrated and discussed.
\end{abstract} Received Date: September 15, 2017 Accepted Date: September 28, 2017 Published Date: September 29, 2017

Citation: Scherlag, B.J., et al. Replicate Imaging of a Unicellular Plant Through a Glass Barrier Using Fine Iron Particles: Evidence for Electromagnetic Energy Transfer. (2017) Lett Health Biol Sci 2(2): 82- 85.

DOI: $10.15436 / 2475-6245.17 .022$

Keywords: Euglena gracilis, Unicellular plants, Nano-sized iron particles, Electromagnetic energy

\section{Introduction}

In our previous studies we developed a novel method for imaging the electromagnetic fields generated by plant and animal tissues $^{[1-4]}$ using a solution containing fine iron particles and a Prussian blue stain (PBS) for iron. We have also shown that these electromagnetic fields can pass through glass ${ }^{[5]}$ (Figures 3 and Figure 5), as well as other types of barriers ${ }^{[6]}$ to be captured using the same imaging technology. In the present report we applied the PBS, fine iron particle methodology applied to samples taken from a culture of the single cell plant, Euglena gracilis.

Copyrights: (C) 2017 Scherlag, B.J. This is an Open access article distributed under the terms of Creative Commons Attribution 4.0 International License. 


\section{Methods}

\section{Preparation of Solutions}

A fine iron particle solution was prepared by mixing several grams of powdered iron filings (Edmond Scientific, Co., Tonawanda, NY) in $200 \mathrm{cc}$ of deionized water (resistivity, 18.2 $\mathrm{M} \Omega . \mathrm{cm}$ ). After standing for several hours the supernatant was carefully decanted for sizing of the iron particles. The particle size and distribution of the particles from the supernatant was determined using dynamic light scattering and the zeta potential using phase analysis light scattering by a Zeta potential analyzer (ZetaPALS, Brook haven Instruments Corp, Holtsville, NY). For particle sizing, $1.5 \mathrm{ml}$ of the solution in de-ionized water was scanned at $25^{\circ} \mathrm{C}$ and the median size of the particles was determined to be 2 microns. A similar aliquot of the fine iron particle solution was scanned for 25 runs at $25^{\circ} \mathrm{C}$, to determine the zeta potential measured in millivolts $(\mathrm{mV})$, the zeta potential for these particles was between +5 and -5 millivolt, in the hyper-aggregable range. A solution having diamagnetic properties was prepared by mixing aliquots of a $2.5 \%$ Potassium Ferrocyanide solution $\left(\mathrm{K}_{4} \mathrm{Fe}(\mathrm{CN})_{6}\right.$ and a $2.5 \%$ hydrochloric acid solution $(\mathrm{HCl})$. Also added were two parts of the fine iron particle solution. The composite solution is abbreviated throughout the manuscript as "PBS Fe2."

For ancillary studies a similar solution with paramagnetic properties was prepared by mixing aliquots of a $2.5 \%$ Potassium Ferricyanide solution $\left(\mathrm{K}_{3} \mathrm{Fe}(\mathrm{CN})_{6}\right.$ and a $2.5 \%$ solution of $\mathrm{HCl}$. Also added were two parts of the fine iron particle solution. The composite paramagnetic solution is abbreviated throughout the manuscript as "PBS Fe3."

\section{Procedures}

Using a clean glass slide $(25 \mathrm{~mm} \times 75 \mathrm{~mm} \times 1 \mathrm{~mm}$ width) as a base, a clean coverslip (24 $\mathrm{mm} \times 50 \mathrm{~mm} \times 0.017$ width) was placed onto the base. Using a transfer tube, a drop of media containing Euglena gracilis, a one-celled mobile plant (Carolina Biological Supply, Co., Burlington, NC) was applied to the middle of the coverslip and a second cover slip applied to create a "sandwich" (SDW). Another coverslip SDW containing either the PBS Fe2 or PBS Fe3 solution was then applied offset to the first so that part was in direct contact with the underlying SDW (active zone) whereas a part of the second SDW was in the area of non-contact (control zone).

Area measurements of the actual encysted cells in the evaporated deep well slides were compared to the areas of the encysted cells imaged through the glass barrier separating the two coverslips. We used the Image Pro-plus histomorphometry software program (Media Cybernetics, Inc., Rockville MD) to compare the area of several of the actual encysted cell randomly selected from the evaporated deep well slides of 4 different experiments (21 values) with those from the cells imaged though the glass barrier from 6 of the coverslip experiments (17 values).

\section{Statistical Analysis}

Means of the areas of the actual encysted cells seen in the evaporated deep well slides were compared with those obtained through the glass barrier separating the paired coverslip using an unpaired T-test. A p value of 0.05 was considered significant.

\section{Results}

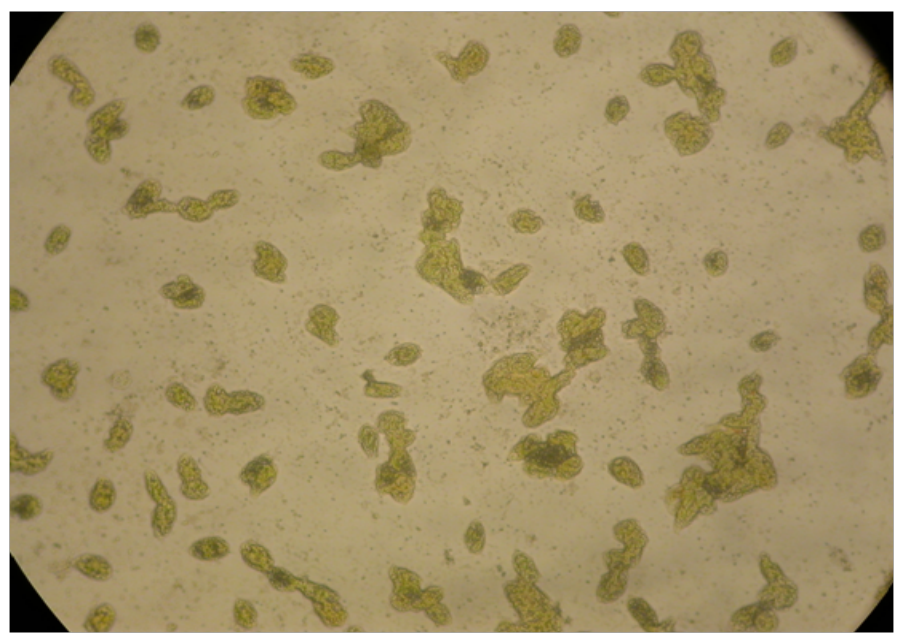

Figure 1: A microphotograph illustrated the encysted cells taken at 24 hours after the culture media had evaporated in the uncovered deep well slide. Most of the cells became rounded or elliptical in shape while still retaining their green coloration. Magnification 10X.

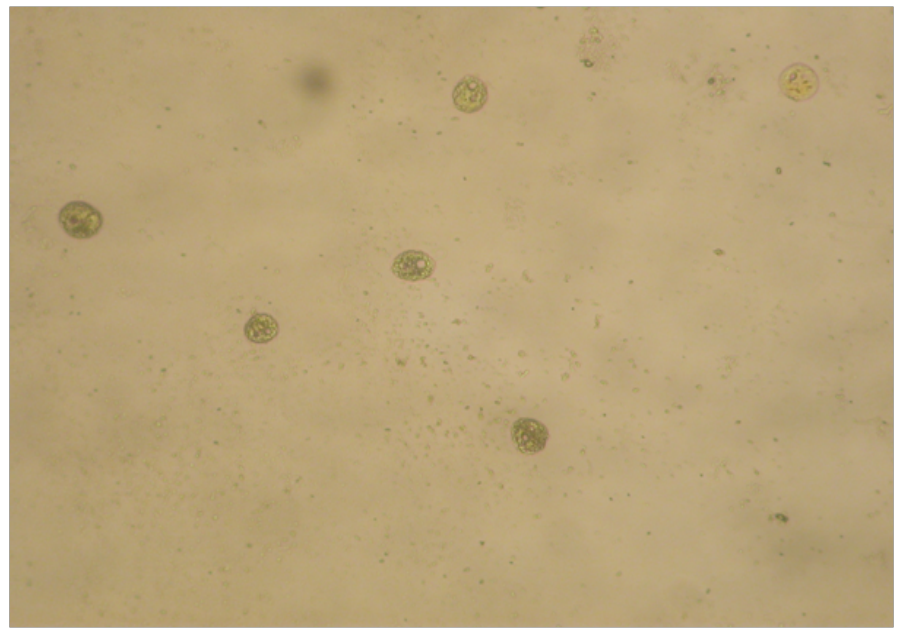

Figure 2: shows the images of the encysted cells in the second SDW containing the PBS Fe 2 or PBS Fe 3. Magnifications 20X.

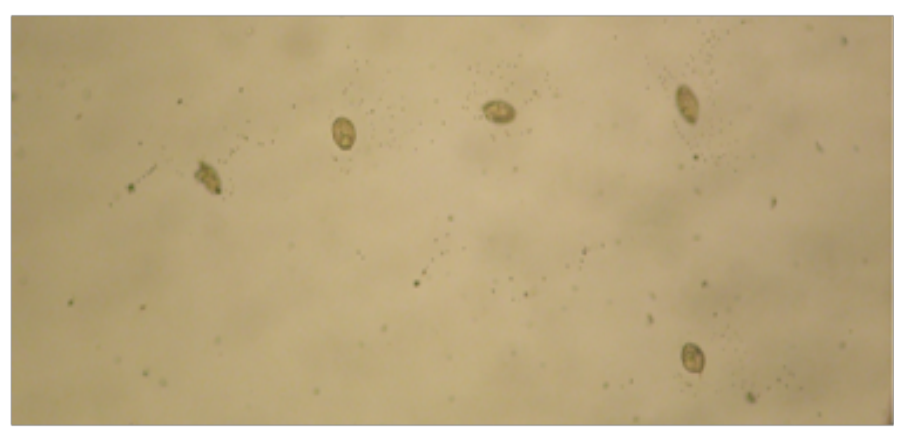

Figure 3: In the PBS solution, the replicate images showed small crystals and/ or iron aggregates which clustered around the replicate cells. Magnification 40X. 


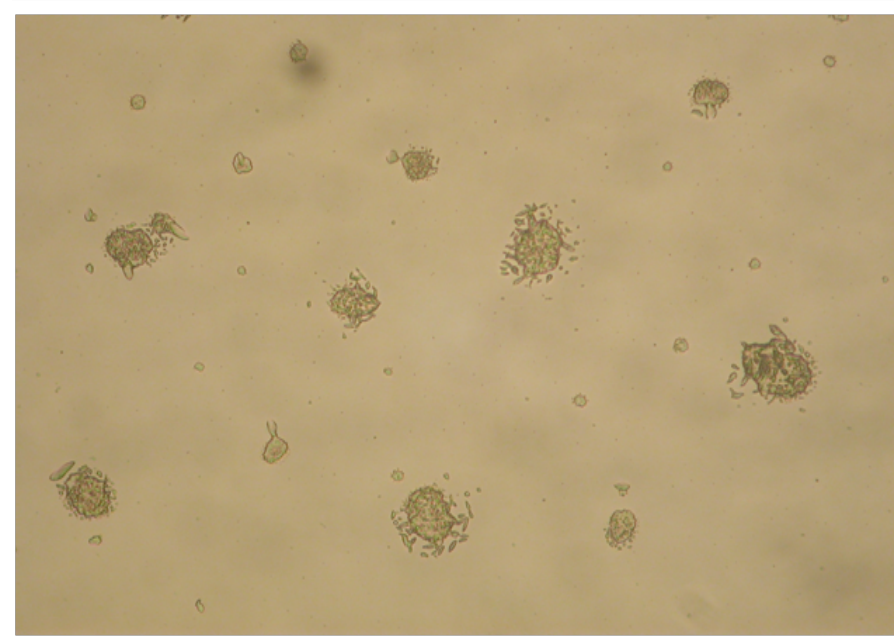

Figure 4: In the PBS Fe3 solution the perimeter of the replicate images were directly contacted by different sizes and shapes of $\mathrm{Fe} 3$ crystals. Magnification 20X.

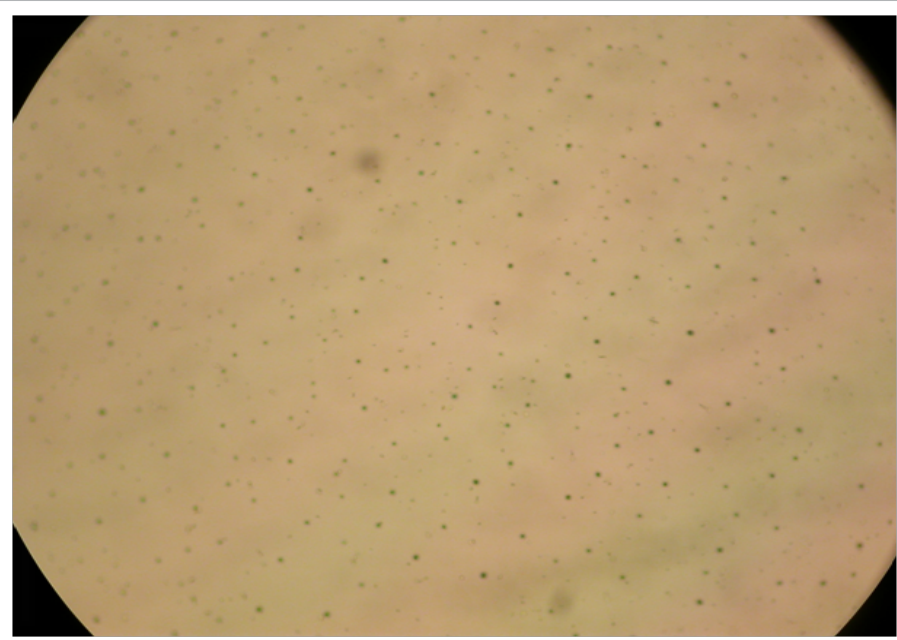

Figure 5: Shows the area of the SDW which was offset so that it did not overlie the SDW containing the Euglena microorganisms. Note that only iron aggregates are seen dispersed in this zone which served as a control. Magnification 20X.

Table 1: The comparison of the area of 21 actual encysted cells randomly selected from the evaporated deep well slides with 17 cells imaged though the glass barrier from the coverslip experiments. There was no significant difference between the two groups, $\mathrm{p}=0.4$.

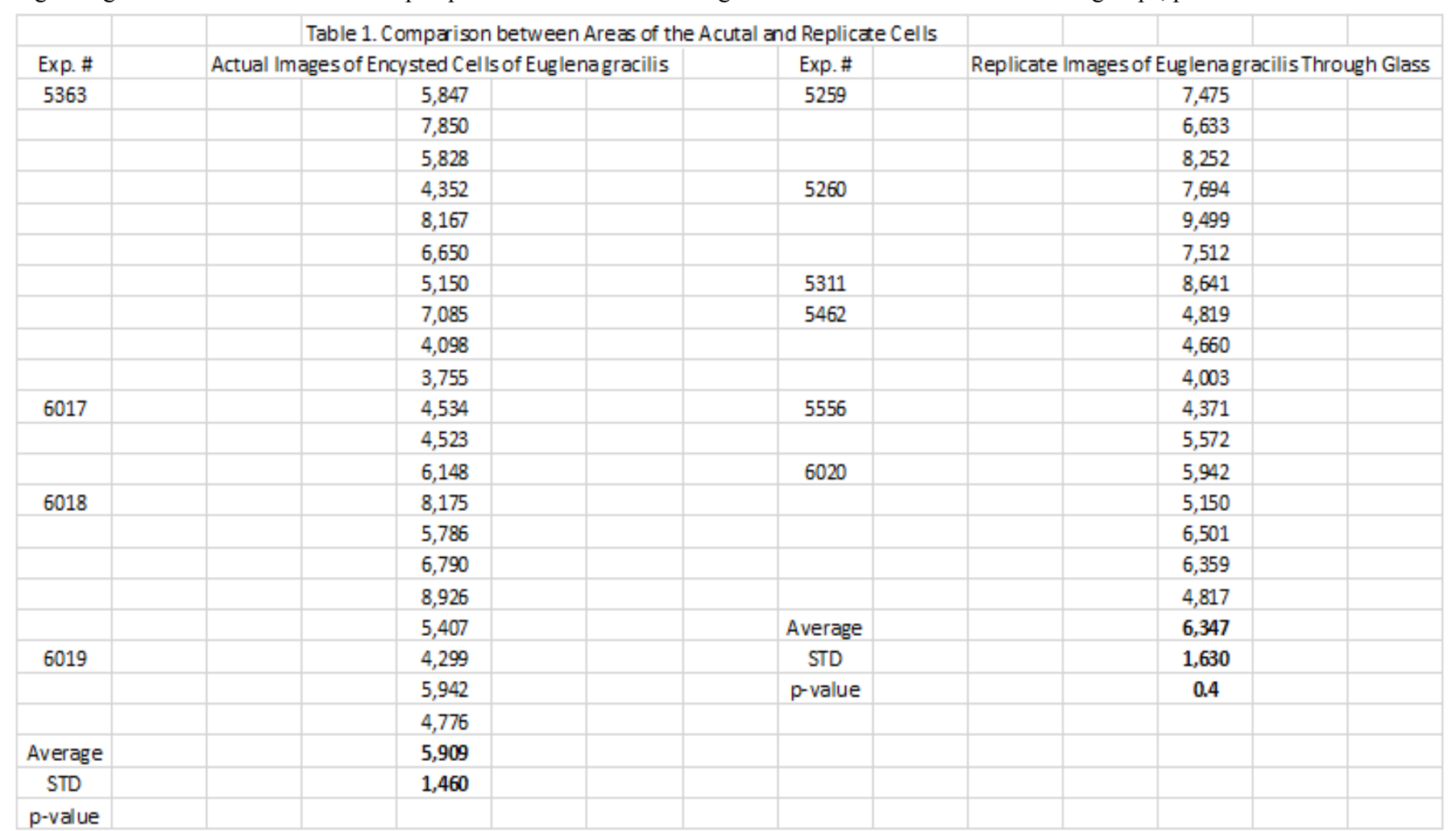

\section{Discussion}

\section{Major findings}

In the present study, living unicellular plant cells which undergo an encysted state in unfavorable environments, i.e., liquid culture evaporation, were enclosed in an SDW with a second SDW overlying the first. The second SDW contained either a diamagnetic, $\mathrm{PBS} \mathrm{Fe} 2^{[7]}$ or paramagnetic, $\mathrm{PBS} F \mathrm{Fe}^{[8,9]}$ solution. We recorded replicate images that passed through a $0.034 \mathrm{~mm}$ glass barrier between the two SDWs. There was no significant difference in the areas encompassed by the replicate images of the encysted cells and those of the actual encysted cells observed in deep well slides after the culture media had evaporated.

\section{Background}

The development of a novel and simplified method for the detection of electromagnetic signals ${ }^{[1]}$ emitted by electron transport during photosynthesis and cellular respiration of living plant an animal tissues has been described in several recent reports from our group ${ }^{[2-6]}$. Furthermore we have previously reported that a living animal tissue, i.e., human hair follicle, interacts differently when exposed to a diamagnetic (Ferrocyanide) 
or a paramagnetic (Ferricyanide) solution. Specifically, electromagnetic energy emanating from hair follicles or actual magnet fragments caused surrounding ferricyanide crystals and incorporated iron aggregates of the evaporating solution to adhere to the follicle; whereas, the ferrocyanide crystals and incorporated iron aggregates were deposited at a distance from the follicle and shaft ${ }^{[10]}$. In the present study the images that appeared through the glass barriers also displayed crystallization. This was more prominently seen in the replicate images developed in the paramagnetic, ferricyanide solution in which relatively large crystals were adherent to the cell images.

\section{Implications}

If in fact, the crystallization evidence, albeit indirect, suggest that the replicate images are inherently electromagnetic, several questions arise:

1. Are these virtual images of the Euglena cells in a vegetative but still living state?

2. Could these images still be captured at some distance after passing through the glass barrier?

3. Can these replicates be revitalized in the same way as the encysted cells seen in the deep well slides after evaporation caused them to encyst. Further experiments may provide evidence to address some of these questions.

\section{Limitations}

No direct measurement of electromagnetic fields emanating from these actual encysted or replicate plant cells has been performed. Others have used a highly sensitive atomic magnetometer to measure the electromagnetic field emanating from a giant plant ${ }^{[11]}$. Their result was on the order of 0.6 Gauss. It would be expected that detection of the biomagnetic signal emitted by single cell plants, even in clusters would be immeasurably smaller.

\section{Conclusions}

In the present study we were able to consistently demonstrate that replicate images of the single cell plant, Euglena gracilis, can be retrieved through a glass barrier. Evidence was presented suggesting that these replicate images had inherent electromagnetic properties.

Funding Source: An unrestricted grant from the Wilton and Helen Webster Research Foundation through the Oklahoma Research Foundation

Conflict of Interest: None declared.

\section{References}

1. Scherlag, B.J., Sahoo, K., Embi, A.A. A Novel and Simplified Method for Imaging the Electromagnetic Energy in Plant and Animal Tissue. (2016) Journal of Nanoscience and Nanoengineering 2(1): 6-9.

Pubmed $\mid$ Crossref $\mid$ Others

2. Scherlag, B.J., Huang, B., Zhang, L., et al. Imaging the Electromagnetic Field of Plants (Vigna radiata) Using Iron Particles: Qualitative and quantitative correlates. (2015) Journal of nature and Science 1: e61. Pubmed $\mid$ Crossref $\mid$ Others

3. Embi, A.A., Jacobson, J.I., Scherlag, B.J. Demonstration of Inherent Electromagnetic Energy Emanating from Isolated Human Hairs. (2015) Journal of Nature and Science 1(3): e55.

Pubmed $\mid$ Crossref $\mid$ Others

4. Embi, A.A., Scherlag, B.J. Human hair follicle biomagnetism: potential biochemical correlates. (2015) Journal of Molecular Biochemistry 4: 32-35.

Pubmed $\mid$ Crossref $\mid$ Others

5. Embi, A.A., Scherlag, B.J. Demonstration of Human Hair Follicle Biomagnetic Penetration Through Glass Barriers. (2016) International Journal of Materials Chemistry and Physics 2: 71-74.

Pubmed $\mid$ Crossref $\mid$ Others

6. Embi, A.A., Scherlag, B.J. Detection of Bioelectromagnetic Signals Transmitted Through the Exoskeleton of Living Land Snails. (2015) International Journal of Animal Biology 1: 302-305.

Pubmed $\mid$ Crossref $\mid$ Others

7. Tan, Y.S., Webster, R.D. Electron-Transfer Reactions between the Diamagnetic Cation of $\alpha$-Tocopherol (Vitamin E) and $\beta$-Carotene. (2011) J Phys Chem B115: 4244-4250.

Pubmed | Crossref | Others

8. Sowrey, F.E., MacDonald, C.J., Cannon, R.D. NMR study of electron transfer between paramagnetic complexes: Kinetics of the self-exchange reaction $\mathrm{Fe} 3 \mathrm{O}(\mathrm{O} 2 \mathrm{CCMe} 3) 6(\mathrm{py}) 3 .+/ 0$ (py = pyridine). (1998) J Chem Soc Faraday Trans 94(11): 1571-1574.

Pubmed $\mid$ Crossref $\mid$ Others

9. Figgis, B.N., Gerloch, M., Mason, R. "The crystallography and paramagnetic anisotropy of potassium ferricyanide". (1969) Proceedings of the Royal Society of London, Series A: Mathematical and Physical Sciences 309: 91-118.

Pubmed $\mid$ Crossref $\mid$ Others

10. Embi, A.A., Scherlag, B.J. Demonstration of Biomagnetic Responses of Paired Human Hair Follicles Using Nano-Sized Iron Particles Solution: Inhibition of Diamagnetic crystallization. (2016) International Journal of Materials Chemistry and Physics 2: 84-87

Pubmed $\mid$ Crossref $\mid$ Others

11. Corsini, E., Acosta, V., Baddour, N., et al. Search for plant biomagnetism with a sensitive atomic magnetometer. (2011) J Appl Physics 109: 07470-1-5.

Pubmed | Crossref | Others
Ommega Online Publishers

Journal Name: Letters In Health and Biological Sciences

Journal Short Name: Lett Health Biol Sci
ISSN no: 2475-6245

E-mail: healthandbiosciences@ommegaonline.com

Website: www.ommegaonline.org 